\title{
SUSTAINABILITY IN AUTOMOTIVE TRANSPORT: RUSSIAN AND ITALIAN EXPERIENCE CONCERNING ACTUAL SITUATION AND INTERVENTION TOOLS
}

\author{
G. GENON ${ }^{1}$, E. MAGARIL ${ }^{2}$, R. MAGARIL ${ }^{3}$, L.ABRZHINA ${ }^{2}$, D. PANEPINTO ${ }^{1} \&$ F.VIGGIANO ${ }^{1}$ \\ ${ }^{1}$ Politecnico di Torino, Italy. \\ ${ }^{2}$ Ural Federal University, Russia. \\ ${ }^{3}$ Tyumen State Oil and Gas University, Russia.
}

\begin{abstract}
The air quality in metropolitan areas of Russia and Italy, although with different distribution and intensity, raises similar concerns for the respective public authorities about vehicle emissions, as well as about the stagnation of toxic pollutants in urban areas. This article discusses some typical situations in both these countries.

In order to obtain suitable solutions to diminish this form of impact, different tools that are based on different approaches can be proposed. It is necessary to consider both the practical possibility of application and the cost-benefit balance that takes into account the realization cost and industrial system transformation on one side, and the results in terms of air quality improvement on the other.

The different instruments (technological intervention on engines, chemical modification of fuels, mobility and road infrastructural planning) are presented for the considered countries, and also in more developed European and American areas, with a concentrated interest in areas of applicability, costs and obtained results.

The externality of this form of pollution is presented and discussed, and the aspect of limitation of impact and consequent external costs is evaluated in comparison with monetary and infrastructural costs for emissive system modification.
\end{abstract}

Keywords: air quality improvement, automotive emissions, environmental damage, tools of intervention.

\section{INTRODUCTION}

The air quality in many urban European areas is strongly compromised on account of emissions from automotive transport [1-3], as is indicated in a new report from EEA [4], where the following aspects are outlined:

- The transport sector affects the environment in different ways;

- It is the only main European economic sector for which GHG emissions are increased since 1990;

- Transport emissions of three important pollutants, $\mathrm{SO}_{\mathrm{x}}, \mathrm{NO}_{\mathrm{x}}$ and $\mathrm{PM}$, decreased during the period 2000 to 2013 in the EU: the introduction of emission standards, the gradual renewal of the fleet and the introduction of EU fuel quality limits were important tools for pollution containment.

Figure 1a and b represent GHG emissions in 2013 in comparison with the situation in 2000, while Fig. 2 shows the evolution in the years of the different local and regional pollut- 

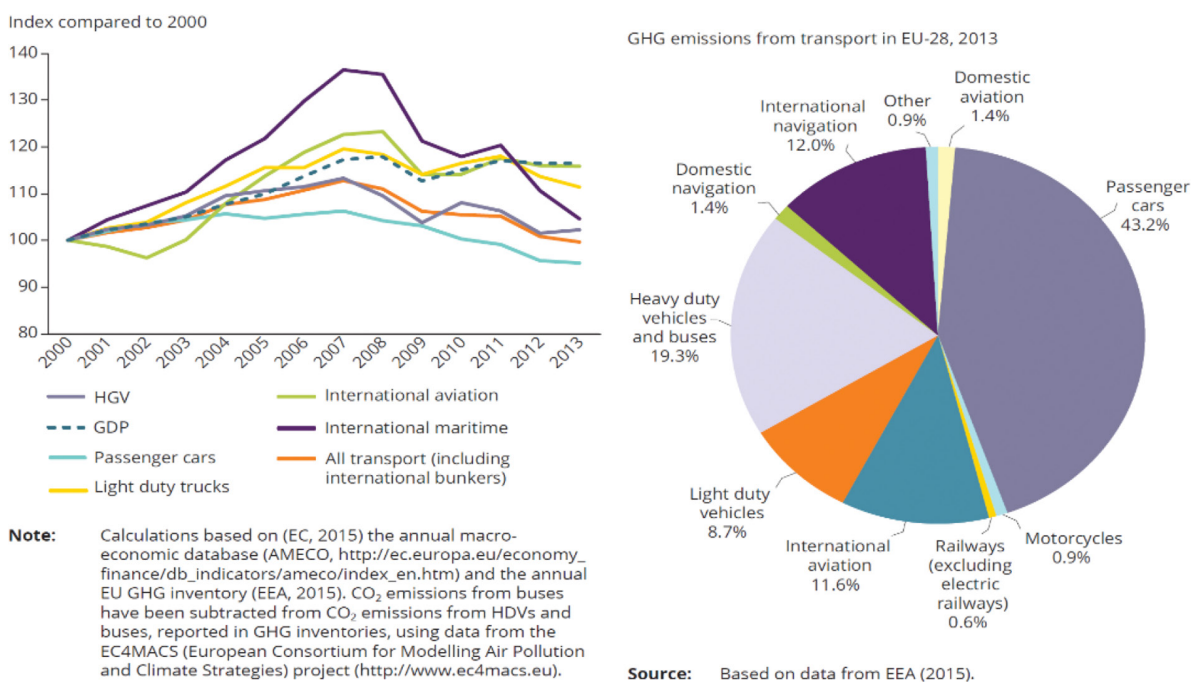

Figure 1: GHG emissions in EU: (a) transport GHG emissions by mode between 2000 and 2013 compared with GDP; (b) Contributions of the different modes of transport to EU transport GHG emissions in 2013 (from [5]).

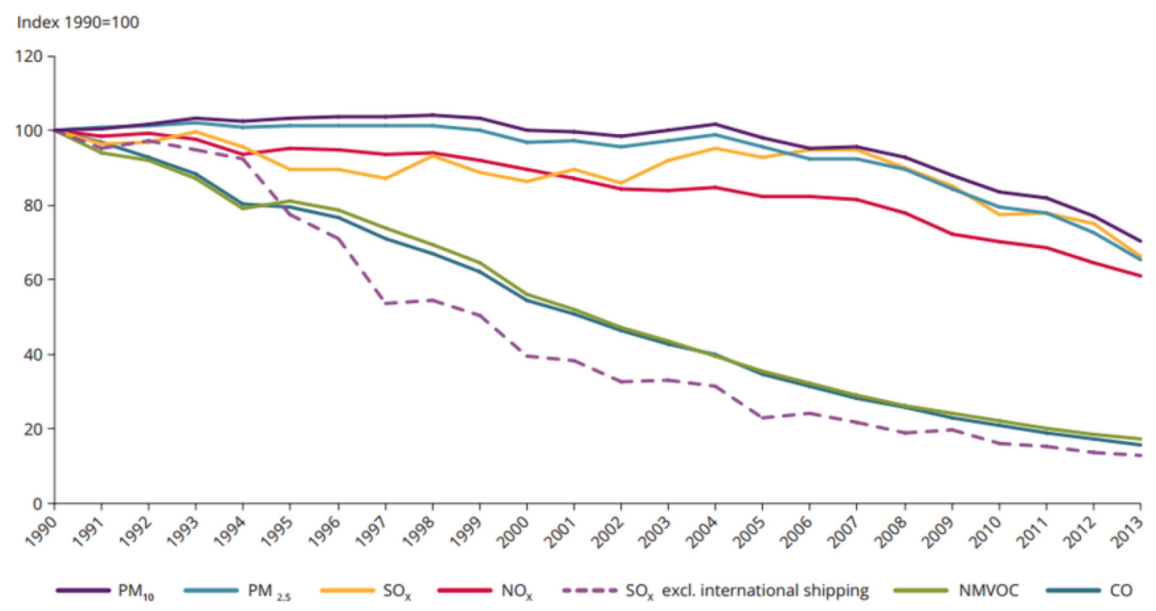

Figure 2: Emissions of air pollutants from the transport sector in the EU - 28 [5].

ants; the good reduction of some forms of pollution ( $\mathrm{SO}_{\mathrm{x}}$, NMVOC) should be appreciated. Although for other parameters $\left(\mathrm{NO}_{\mathrm{x}}, \mathrm{PM}\right)$ some progress is clearly observed, a positive result is not yet attained.

The increase of anthropogenic emissions of the greenhouse gases (GHG) in the Russian Federation (without taking land tenure, land tenure changes, and forestry (LTLTCF) into consideration) gradually slowed down in 2010-2012, and somewhat reduced in 2013 and 2014 , which correlates to the reduction of energy consumption due to some recession in industrial production (Fig. 3). 


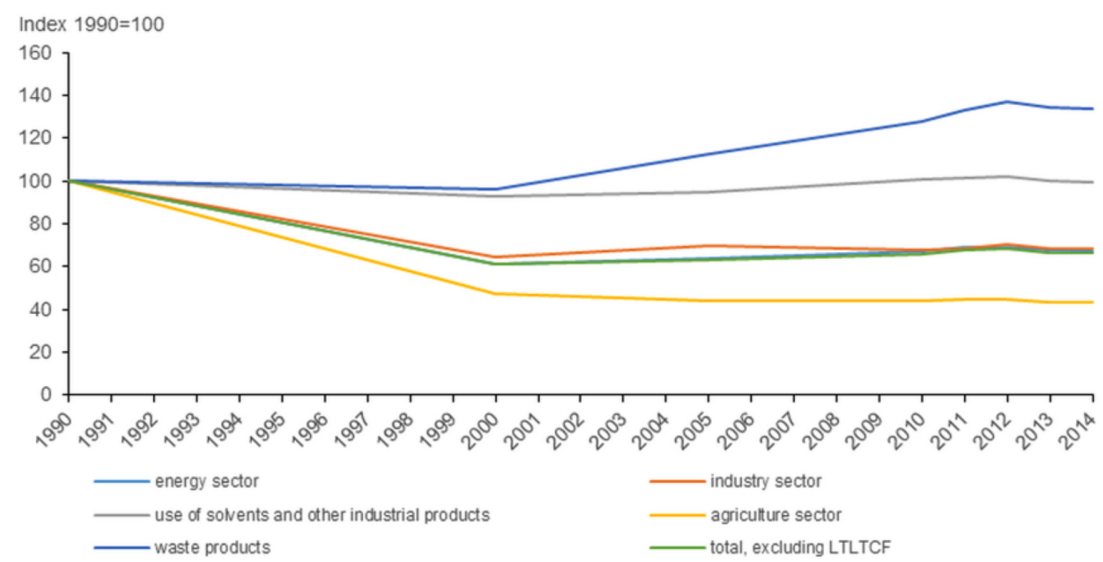

Figure 3: Dynamics of GHG emissions compared to 1990 in Russia (according to [6]).

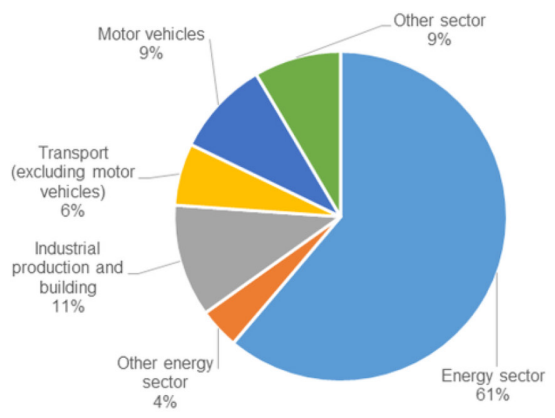

(a)

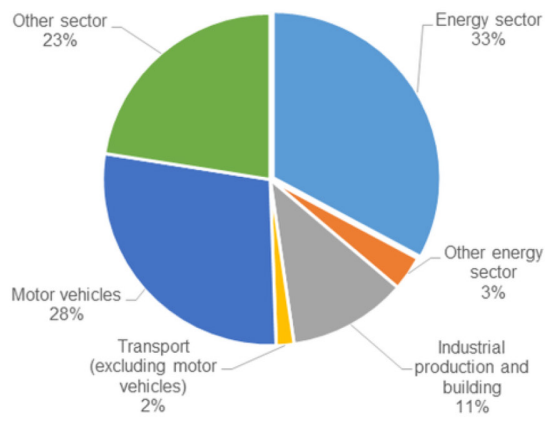

(b)

Figure 4: GHG emissions by the sectors (2013): (a) Russia; (b) Italy (on the basis of data [8]).

Grouping the emissions by the sectors is based on the methodology of the Intergovernmental Panel on Climate Change according to which emissions from combustion of all kinds of fossil fuels belong to the energy sector as well as the technological emissions and leakages to the atmosphere of the fuel products independently of the economy branch they take place in $[6,7]$.

Figure 4 shows the contribution of the different sectors to GHG emissions in Italy and Russia. Because most part of the Russian territory is exposed to low temperatures most part of the year, major heat energy is needed to warm up the industrial and residential buildings, and the basic part of the GHG is emitted by the energy sector.

In Italy, which has a Mediterranean climate and, as a result, with a significantly lower capacity of energy industry, the share of transportation in the total greenhouse gases emissions is noticeably higher as in many other European countries with mild climatic conditions.

Figure 5 shows the dynamics of the relative amount of the pollutant emissions, the most prevailing pollutants emissions index as compared to that of 2000 and the specific emissions per GDP unit, per capita, and per energy unit index for Russia as compared to that of 2010.

Due to the increase in industrial production and to the corresponding increase in energy consumption as well as to the significant development of the motor vehicle industry in the 


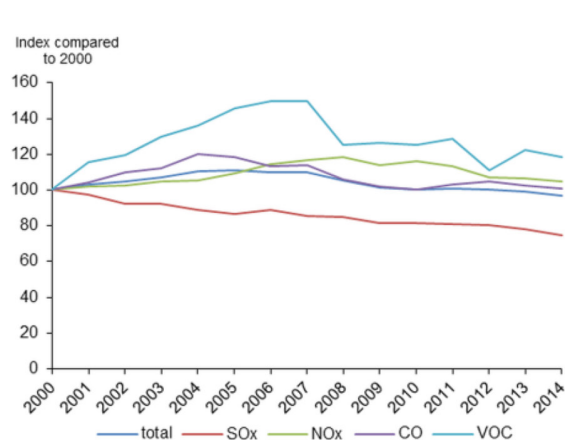

(a)

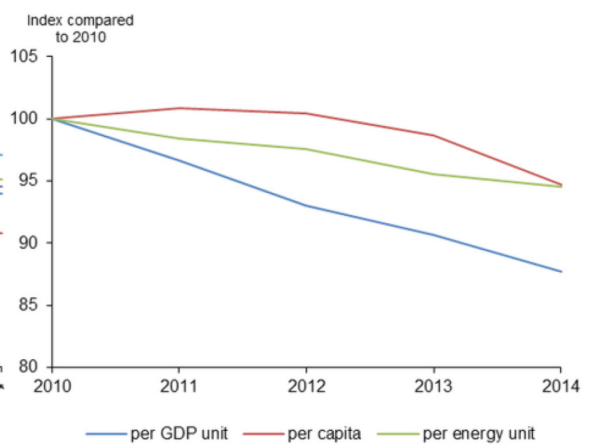

(b)

Figure 5: The dynamics of the relative amount of the pollutant emissions (derived from the data [9]): (a) the most prevailing pollutants emissions index as compared to that of 2000; (b) the specific emissions per GDP unit, per capita, and per energy unit index as compared to that of 2010 .

country after 2000 [9], the majority of the components showed a rise despite a decrease in the total pollution volume. At the same time, the motor transport contribution to the total emissions of toxic substances increased from $40.9 \%$ in 2010 to $44.1 \%$ in 2014.

In general, the specific emissions (Fig 5b) decreased, thus showing the effectiveness of the environment protection measures formulated by the state environmental policy [10], including improving the quality of the fuels used. Besides, in 2013-2014, a certain percentage in the decrease of the specific emissions was due to the crisis in the economy and corresponding energy consumption reduction.

\section{POLLUTION LIMITATION}

\subsection{General and local aspects of the transport emissions}

The consequences of GHG emissions and toxic pollution can be considered from different points of view, and different solutions to this problem must be proposed.

As regards the climate change, vehicles emission is a very important part of energy production. The individuation of technological solutions as well as the planning decisions and limitation at the source of the phenomenon is required.

The technological and planning intervention tools are valid also for limiting the impact of toxic pollutants. In this case, the need for intervention is increased with reference to the impact on health, while for GHG emissions it is not convenient to account for the local cases, the limitation must be considered in the general framework of the compatibility of energy production. For local pollutants it is mandatory to have a look at the concentration levels arising from pollutants emission, by making specific reference to the threshold values in different areas. The geographical situation and the local capacity of dispersion and dilution of the emitted pollutants in the considered region are very important in this regard. Thus, the situation of North Italy, and Po Valley in particular, where a diffuse and persistent stagnation condition corresponds to a high contribution from traffic [11], must be considered very critical. 


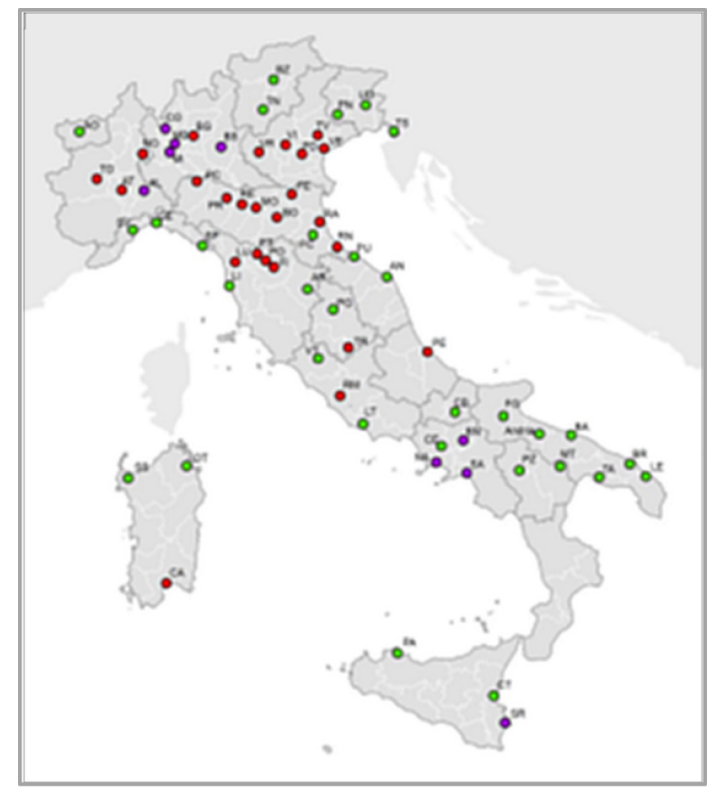

Figure 6: Concentration of the pollutant parameter $\mathrm{PM}_{10}$ in different parts of Italy [12]: •not exceeding; •- exceeds the daily limit value $\left(50 \mathrm{mg} / \mathrm{m}^{3}\right.$; $\max 35$ days a year); • - exceeds the limit value $\left(40 \mathrm{mg} / \mathrm{m}^{3}\right)$.

Figure 6 shows the local concentrations of PM (well correlated with traffic emission) in different parts of Italy. It can be clearly observed that there is quite a bad diffused situation in the North of Italy, and that there is a consequent need to individuate potential solutions.

In a large number of cities in Russia, such as Moscow, Voronezh, Rostov-on-Don, Krasnodar, Orenburg, Ekaterinburg, St.-Petersburg, Nizhny Novgorod, Saratov, Tyumen, Samara, Kazan, Perm, Volgograd, and Novosibirsk, motor transport contribution to the total emissions amounts to $50 \%-95 \%$ [13].

Thus in Ekaterinburg, a big industrial centre, although the main sources of atmospheric pollution are the motor and railway transport industry, the mechanical engineering and metal-working industries, ferrous and non-ferrous metallurgy, construction and chemical industry plants and heat power plants, the motor transport alone contributes to $85 \%$ of anthropogenic emissions. The city is included in the list of those with the highest pollution level; especially important are the increased concentrations of formaldehyde, nitrogen oxide, benzo $(\alpha)$ pyrene, and ethylbenzene, while the level of air pollution with nitrogen oxide and suspended matters increased during 2009-2014 [13].

The high pollution levels of the listed substances have a significant impact on health; especially dangerous is the concentration of benzo $(\alpha)$ pyrene that substantially exceeds the maximum permissible concentration, while benzo $(\alpha)$ pyrene is the strongest carcinogen. The climatic and economical peculiarities make it necessary for specific approaches to solve the environmental problems caused by toxic substances emissions by the transportation industry, while the ecological situation in the big cities requires urgent and highly effective environmental protection measures. 


\subsection{Instruments for pollution reduction}

Following are the useful instruments in different schemes and with different effectiveness on the reduction of environmental impact:

- limitation in the use of more polluting transport systems;

- use of more acceptable fuels;

- technological intervention in engine design;

- rational planning of traffic distribution.

The first effective but difficult solution, should be to contain automotive movement by proposition home-jobs, with the purpose of obtaining the satisfaction of employment necessities without an associated need for movement. This solution requires a different type of work organization and it must be carefully examined from the point of view of the practicality. It can be in limited in some cases, but in perspective it must be absolutely encouraged.

In the same sense, with the aim to limit pollution, the choice of public transport must be considered, and environmentally suitable means of transport should be adopted. In addition, in this case, the infrastructural cost must be considered, and the need to obtain large public approval of the systems is a required condition. However, the effect, as demonstrated in some well-operating areas in North Europe, has been found to be absolutely satisfactory.

Tax measures are very promising in terms of providing means to improve environmental safety. The funds from transportation taxes may be utilized for the development of road infrastructure in the regions $[14,15]$.

The acting systems of tax regulations in various countries have different approaches to motivate improvement of the produced fuel quality, but they do not differentiate the tax rates based on the carbon dioxide emission from fuel combustion. Meanwhile, the carbon dioxide emission can significantly differ within one fuel environmental class.

Earlier it was shown that the specific carbon dioxide emissions are directly dependent on the density of the fuel used and generally correlate with the toxic substances emissions under these conditions [16]. This determines the necessity to reduce the density of the produced gasoline and diesel fuel to the lower limit within the given quality category, which can be achieved by changing the temperature range of distillation of gasoline and diesel fractions. This technological approach does not involve additional investments, but in order to drive petrol manufacturers to produce fuel with the minimum allowable density there is a need to use economically stimulating methods. In this respect, it is advisable to introduce environmental tax, taking into account not only the fuel environmental class but its density as well $[17,18]$ :

$$
T_{e l_{i}}=R_{i} \cdot G_{i}=\left(R_{m}+R_{a d}\right) \cdot G_{i}
$$

where $T_{e l_{i}}$ is the quantity of environmental tax on gasoline/diesel fuel of the i-th environmental class, monetary units; $R_{i}$ is the rate of an environmental tax on motor fuel, monetary units/t; $G_{i}$ is the weight of the sold fuel of the $\mathrm{i}$-th environmental class, $\mathrm{t} ; R_{m}$ is the main rate of the environmental tax on the fuel of the i-th environmental class, monetary unit/t, depending on the fuel environmental class; $R_{a d}$ is an additional rate of the environmental tax on the $\mathrm{i}$-th type of fuel, monetary units /t, to be determined depending on the fuel density. 
A similar tax mechanism for refineries to motivate them to improve the environmental characteristics of the produced fuels could be introduced in the limits of one state or at the inter-governmental level.

The adoption of different fuels (bio-fuel to limit GHG emissions, reformulated gasoline to reduce the pollutant formation) can lead to important advantages, that have been largely described in specific literature, but the whole cycle of production and use (from agricultural products, or chemicals, to fuel use) must be considered with a Life Cycle Assessment approach, in order to evaluate the real benefits and limits of this type of process innovation. In addition, the operating costs must be carefully reviewed, and for bio-fuels or, in general, for products derived from agriculture, the aspects of social and ethical compatibility must be considered.

The potential solutions to the problem of atmospheric air pollution in many Russian cities differ from that applicable for warm climate countries. Thus, the low-temperature climatic conditions of Russia strongly reduce the possibility of use of biofuels and gasoline-alcohol mixtures. On the other hand, a dramatic improvement in the quality of the traditional gasoline and diesel oils is limited by the capacities of the oil-refining industry and need substantial investments $[19,20]$. Therefore, it is important to use fast-realized methods that do not require substantial costs but at the same time provide substantial effect on the improvement of fuel quality and in the decrease of negative consequences in motor vehicle operation. To make objective decisions in this field, it is necessary to use effective methods of evaluation of the environmental measures adopted. This allows to substantiate the choice of the alternatives while comparing the maximum value of the integral environmental and economical effect; the realization of the environmental measures on the basis of their effectiveness considering economic and environmental components and the increase of the economical motives in environmental decisions making [21].

A unique method regarding its simplicity and effectiveness is the use of the effective additive to fuels, which gives the complex positive effect for gasoline and for diesel fuel as well $[22,23]$. Table 1 shows some positive effects of the ultra-small additive concentrations.

The use of the multifunctional additive can significantly reduce the environmental load from motor transport in large cities as well as fuel consumption and the need for high-octane gasolines.

The technological intervention in engines design is a common practice, strongly encouraged by public authorities and car manufacturers; it can lead to important results in terms of emission reduction. Counter-aspects that must be considered are the long life cycle of the existing vehicle fleet, the difference between theoretical (laboratory results) and practical (road emissions) performances and the absence of effect on non-exhausted emissions.

Some interdisciplinary innovative decisions to improve engines condition can significantly increase fuel economy and environmental characteristics. One such decision is to use technology for plating the working surfaces with a protective-catalytic nano-layer of metal catalyzing the gasification reaction for eliminating motor carbon formation[24, 25]. The elimination of the carbon formation improves the heat transfer through the engine walls, resulting in the decrease of the formation and, correspondingly, the emission of oxides of carbon and nitrogen. Specific fuel consumption in the engine, requirements of gasoline octane level and polycyclic aromatic hydrocarbons emission are also reduced. The use of this technology is effective for both new and for used engines as well.

Another possible useful tool is the evaluation of the effect of different traffic distribution on air quality. To obtain the opportunity to regulate and to re-distribute the traffic fluxes, it is 
Table 1: Improving the operational and environmental characteristics of vehicles by the introduction of the multifunctional fuel $(9.25 \mathrm{ppm}$ in gasoline and $27.75 \mathrm{ppm}$ in diesel fuel).

\begin{tabular}{lll}
\hline Characteristics & Gasoline engines & Diesel engines \\
\hline Fuel consumption & $-5 \%-12 \%$ & $-4 \%-7 \%$ \\
Reduction of emission & $-15 \%-30 \%$ & $-15 \%-17 \%$ \\
$\mathrm{CO}$ & $-20 \%-26 \%$ & $-20 \%-22 \%$ \\
$\mathrm{NO}_{\mathrm{x}}$ & $-8 \%-35 \%$ & $-35 \%-37 \%$ \\
$\mathrm{CH}$ & $-95 \%-96 \%$ & - \\
benzo(a)pyrene and its analogues soot & - & $-40-50 \%$ \\
& $6-10$ items & - \\
Decrease of requirements to octane number of & & +3 items \\
gasoline & - & - \\
Cetane number & $-15 \%-20 \%$ & \\
Vaporization loss of gasoline &
\end{tabular}

required to consider a model of atmospheric dispersion with the effects of modified traffic distribution on urban areas air quality, and the consequent advantages in terms of compatibility. Both the aspects of the real possibility to govern the traffic and of the pre-vision of the air effects of the modified scenarios are very difficult tasks, but on account of its useful objective this approach should be considered [26].

In Russia, the significant factor of the engines fuel economy increase, except those mentioned above, is the quality improvement of the pavement, the current condition of which, in the majority of regions, is unsatisfactory.

The previously indicated instruments must be evaluated by considering their effectiveness, in terms of pollution limitation, as well as the practical applicability, costs, infrastructural innovations and socio-economic transformations that are required. All these aspects must be evaluated for a final political choice.

On account of the fact that it is necessary to compare the structural or operating costs with the benefits in terms of impact reduction, an evaluation of the reduced externalities is very important.

\section{COSTS AND EXTERNALITIES REDUCTION}

The adoption of solutions that are able to decrease the impact of automotive transport on air quality leads necessarily to costs, but at the same time, also to an improvement in the air quality, and consequently in a reduction of the externalities. A comparison of these two aspects is an important choice criterion, in order to evaluate the effectiveness of a proposed intervention, and its relevance to the framework of the required activities.

The steps that must be considered in this evaluation are:

- emission evaluation with and without an individuated intervention;

- cost estimation for the adoption of the intervention;

- estimation of the effect on air quality (on the basis of air modelling); 
- estimation of health and environmental effects;

- economic evaluation of the decreased anthropogenic impact;

- final comparison of costs and benefits.

Definition of emissions is the starting point for the estimation of benefit and cost; afterwards two opposing scenarios must be defined, one with the adoption of a required measure and the other without (both scenarios must be considered in their dynamic development).

The use of acceptable emission factors for technological aspects or reliable forecasts for non-structural solutions is a required condition for the individuation of quantitative future emissions scenarios. This aspect requires careful investigation of each proposed technology, and a realistic estimation of the possibilities from planning traffic modification.

As an example, Fig. 7 shows an estimation of VOC emission reduction (in comparison with business-as-usual situation) in the United States with adoption of procedures established from Clean Air Act (CAAA), for the period 2000-2020, based on the data from [27].

As concerns the costs for implementation of measures, they must be defined in terms of industrial production, research and development, capital investment, productivity, employment, consumption of resources and territorial modification. These costs can be estimated with an approach based on unit costs that can be obtained by collecting information from intervention operators on the expenditures that are associated with specific control measures.

It is important to note that while process or technological approaches can be quite simply evaluated in terms of cost, investment for mobility modification, different territorial planning, interventions on structure and average age of vehicle fleet involves many social and economic aspects that must be specifically considered.

The procedure useful to determine the modification in air quality as a consequence of an assumed emission scenario starts from emissive fluxes, is also used to evaluate the benefits in terms of air quality.

To prevent or to decrease the negative consequences of the vehicles operation, their appropriate economical evaluation is needed. As a rule, only the negative effects inflicted by the toxic substances emissions are taken into account while ignoring the negative environmental effects of carbon dioxide emissions and the consumption of oxygen during the fuel combustion. Meanwhile, at the present stage, the global reduction of energy resources and the increase of the anthropogenic GHG emissions in the atmosphere take place. On the other hand, the amounts of atmospheric oxygen consumption for technogenic purposes significantly exceeds its consumption by the respiratory activities of the living inhabitants on the planet and, in major regional plans, exceeds the volume of oxygen production in these regions. These negative effects are global in nature and should be considered as a part of common externalities arising from transport operation [28].

Thus, while economically evaluating the environmental damage to the atmospheric air caused by motor vehicle operation it is advisable to consider three components: negative effects of the polluting toxic substances emissions $D_{t s}^{e l}$, carbon dioxide emissions $D_{\mathrm{CO}_{2}}^{e l}$, and atmospheric oxygen consumption by the motor vehicle operation $D_{O_{2}}^{e l}$. Thus, a summary of the ecological damage $D^{e l}$ can be evaluated by using the formula (2):

$$
D^{e l}=D_{t s}^{e l}+D_{\mathrm{CO}_{2}}^{e l}+D_{\mathrm{O}_{2}}^{e l}
$$

The economic evaluation of the cost of the greenhouse gas emission decrease by 1 ton can be accepted as a specific damage caused by carbon dioxide emissions, which can be determined 


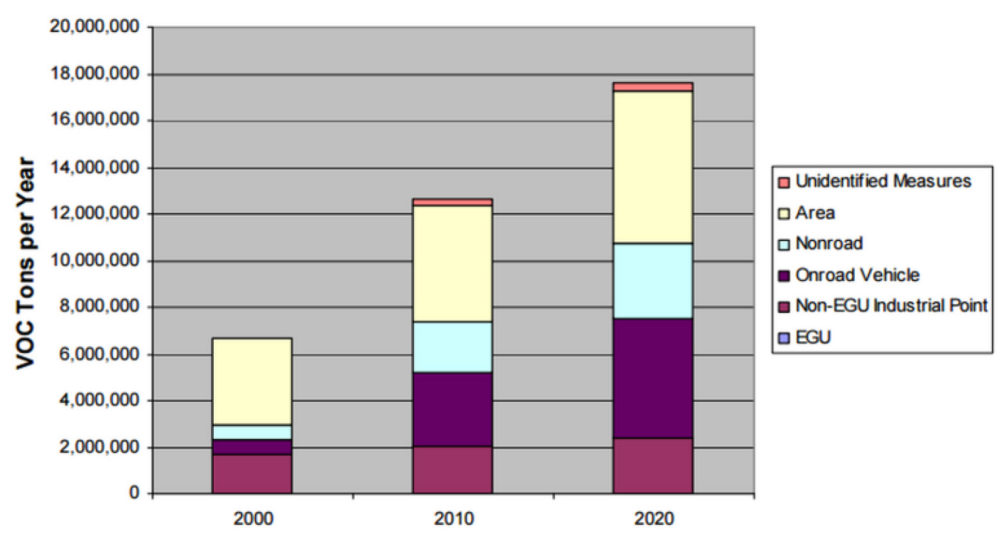

Figure 7: VOC reductions associated with CAAA compliance by source category.

individually at the state level and at the international level as well, similar to the experience of the Kyoto Protocol [29]. Environmental damage from oxygen consumption for fuel combustion can be calculated based on the recovery cost of 1 ton of free oxygen, defined as the sum of the costs of the whole complex of reforestation against the free oxygen produced by the forests and the actual mass of oxygen consumed during the period under consideration.

A more complete account of the negative externalities increases the decision-making objectivity in the implementation of environmental protection measures and the requirements for compensating the negative environmental impacts by the producers of these externalities.

The benefits of air quality improvement is chiefly of health, which is evaluated as risk reduction on the basis of epidemiological studies. In parallel, there is the need to consider the ecological and welfare benefits arising from increased air quality as well as its effects on crops and materials.

The comparison between sustained costs and advantages in terms of reduction of externalities is the final step of the over-indicated procedure, and it establishes an important evaluation criterion for public authority.

Some further aspects in this comparison must be taken into account, and particularly:

- non-linearity in time of costs that require compensation and reduction of impact phenomena corresponds to the fact that it is necessary to compare the short-, medium- and longterm perspective; consequently some form of time planning is required;

- the intensity of intervention towards atmospheric emission presents normally a non-linear influence on costs and advantages;

- the reliability of the comparison is connected from one side to the definition of realistic indication of costs, and from the other side on the capacity to forecast the influence of reduced effect of pollution on health and related costs.

\section{CONCLUSIONS}

The evaluation of emissive fluxes is related, on one side, to emission factors, and, on the other side, to the traffic fluxes and vehicle fleet, that are dependent on political choices and socioeconomic aspects. The effect of the fluxes on air quality can be determined by using 
well-consolidated model approaches. On the other hand, it should be noted that the formation of secondary pollutants (fine PM, ozone, toxic organic components) is very difficult for investigation from the standpoint of chemical kinetics.

The impact of pollution on health is, in general, difficult to estimate due to the complexity of the human factors involved. It is further complicated by the necessity to distinguish the responsibility of different sources, very frequently leading to the same atmospheric pollutants.

The evaluation of intervention costs must take into account not only technological aspects, but also, chiefly, modification of life style, mobility and structured metropolitan areas infrastructures.

All these aspects contribute to the difficulties of individuation and implementation of the best choices to satisfy the mobility requirement of modern society and at the same time to guarantee compatibility.

It is necessary to stimulate the environmental decisions aimed at decreasing the negative consequences of motor vehicle exploitation, considering the real possibilities of the economy, climatic peculiarities, and environmental situation on the state level. Some inter-governmental decisions are also necessary to provide the stable development of transportation in the longterm future.

\section{ACKNOWLEDGEMENT}

This research was supported by Act 211 Government of the Russian Federation, contract № 02.A03.21.0006.

\section{REFERENCES}

[1] Ionescu, G., Apostol, T., Rada, E.C., Ragazzi, M. \& Torretta, V., Critical analysis of strategies for PM reduction in urban areas. UPB Scientific Bulletin, Series D: Mechanical Engineering, 75(2), pp. 175-186, 2013.

[2] Pant, P. \& Harrison, R.M., Estimation of the contribution of road traffic emissions to particulate matter concentrations from field measurements: a review. Atmospheric Environment, 77, pp. 78-97, 2013.

http://dx.doi.org/10.1016/j.atmosenv.2013.04.028

[3] Wang, W., Huang, M., Kang, Y., Wang, H., Leung, A., Cheung, K. \& Wong, M., Polycyclic aromatic hydrocarbons (PAHs) in urban surface dust of Guangzhou, China: status, sources and human health risk assessment. Science of the Total Environment, 409, pp. 4519-4527, 2011 http://dx.doi.org/10.1016/j.scitotenv.2011.07.030

[4] Evaluating 15 years of transport and environmental policy integration TERM 2015, EEA.

[5] European Environmental Agency, Evaluating 15 years of transport and environmental policy integration, EEA Report $n$ 7/2015.

[6] Intergovernmental Panel on Climate Change, available at www.ipcc.ch

[7] Survey of the environment condition and pollution in Russian Federation for 2014, available at www.meteorf.ru/upload/iblock/4c0/Obzor_2014.pdf

[8] IEA $\mathrm{CO}_{2}$ Emissions from Fuel Combustion, OECD/IEA, Paris, 2015, available at wds. iea.org/wds/pdf/Worldco2_Documentation.pdf

[9] State Statistics Federal Service, available at www.gks.ru

[10] The basics of the State policy in the field of Russian Federation ecological development in the period till 2030, available at www.consultant.ru/document/cons_doc_ LAW_129117 
[11] Panepinto, D., Brizio, E. \& Genon, G., Atmospheric pollutants and air quality effects: Limitation costs and environmental advantages (a cost-benefit approach). Clean Technologies and Environmental Policy, 16(8), pp. 1805-1813, 2014. http://dx.doi.org/10.1007/s10098-014-0727-6

[12] ISPRA, IX Rapporto sulla qualità dell'ambiente urbano, Emissioni e qualità dell'aria, 2011.

[13] The annual of the pollutants emissions into the atmosphere air of the Russia cities and regions in 2014, available at www.meteorf.ru/product/ infomaterials/ezhegodniki/

[14] Mayburov, I. \& Leontyeva, Y., Reducing the negative impact of motor transport on the environment: Prospects for the use of fiscal instruments in Russia. WIT Transactions on Ecology and the Environment, 186, pp. 863-874, 2014. http://dx.doi.org/10.2495/ESUS140771

[15] Mayburov, I. \& Leontyeva, Y., Transport tax in Russia as a promising tool for the reduction of airborne emissions and the development of the road network. WIT Transactions on Ecology and the Environment, 198, pp. 391-401, 2015. http://dx.doi.org/10.2495/AIR150341

[16] Magaril, E., Improvement of the environmental and operational characteristics of vehicles through decreasing the motor fuel density. Environmental Science and Pollution Research, 23(7), pp. 6793-6802, 2016. http://dx.doi.org/10.1007/s11356-015-5920-6

[17] Golubeva, A. \& Magaril, E., Environmental tax as an instrument of economic stimulation to improve the quality of motor fuels. WIT Transactions on Ecology and the Environment, 192, pp. 149-159, 2015. http://dx.doi.org/10.2495/ECO150141

[18] Golubeva, A. \& Magaril, E., Improved economic stimulation mechanism to reduce vehicle $\mathrm{CO}_{2}$ emissions. WIT Transactions on the Built Environment, 130, pp. 437-445, 2013.

[19] Magaril, E., The solution to strategic problems in the oil refining industry as a factor for the sustainable development of automobile transport. WIT Transactions on Ecology and the Environment, 190(2), pp. 821-832, 2014. http://dx.doi.org/10.2495/EQ140762

[20] Magaril, E., Increasing the efficiency and environmental safety of vehicle operation through improvement of fuel quality. International Journal of Sustainable Development and Planning, 10(6), pp. 880-893, 2015. http://dx.doi.org/10.2495/SDP-V10-N6-880-893

[21] Abrzhina, L.L. \& Magaril, E.R., Assessment of environmental-economic effectiveness of multifunctional fuel additives. WIT Transactions on Ecology and the Environment, 198, pp. 287-294, 2015.

http://dx.doi.org/10.2495/AIR150241

[22] Magaril, E., Improving car environmental and operational characteristics using a multifunctional fuel additive. WIT Transactions on Ecology and the Environment, 147, pp. 373-384, 2011. http://dx.doi.org/10.2495/AIR110351

[23] Magaril, E., The influence of carbonization elimination on the environmental safety and efficiency of vehicle operation. International Journal of Sustainable Development and Planning, 8(2), pp. 231-245, 2013. http://dx.doi.org/10.2495/SDP-V8-N2-231-245 
[24] Magaril, E., Improving the efficiency and environmental safety of gasoline engine operation. WIT Transactions on the Built Environment, 130, pp. 437-445, 2013. http://dx.doi.org/10.2495/UT130341

[25] Magaril E., Carbon-free gasoline engine operation. International Journal of Sustainable Development and Planning, 10(1), pp. 100-108, 2015. http://dx.doi.org/10.2495/SDP-V10-N1-100-108

[26] Università di Venezia, Piano urbano della mobilità del Comune di Reggio Emilia, Simulazione modellistica dell'inquinamento atmosferico da traffico veicolare in provinciale di Reggio Emilia - Allegato al documento finale, Giugno 2007.

[27] U.S. Environmental Protection Agency (EPA) Office of air and radiation, the benefit and costs of the clean air act from 1990 to 2020, final report - rev A, 2011.

[28] Magaril, E., Abrzhina, L. \& Belyaeva, M., Environmental damage from the combustion of fuels: challenges and methods of economic assessment. WIT Transactions on Ecology and the Environment, 190(2), pp. 1105-1115, 2014. http://dx.doi.org/10.2495/EQ141032

[29] Framework Convention on Climate Change, newsroom.unfccc.int/ 